\title{
O PAPEL POLÍTICO DA CORTE INTERAMERICANA DE DIREITOS HUMANOS PARA EFETIVAÇÃO DE DIREITOS FUNDAMENTAIS NO BRASIL
}

\section{Elaine Dupas ${ }^{1}$ \\ Luciani Coimbra de Carvalho}

\section{RESUMO}

Objetiva-se analisar o papel político do judiciário para efetivação dos Direitos Humanos das minorias e possibilidade do exercício do ativismo judicial pela CIDH. É analisado o conceito de ativismo, legitimidade e limites para averiguar em que medida permite a efetivação dos direitos fundamentais. Será analisada a atuação da CIDH e o ativismo em face à soberania dos Estados, por meio da análise do Caso Gomes Lund e outros vs. Brasil, chocando-se frontalmente com a Lei de Anistia, caracterizando-se como atuação ativista por condenar à implementar políticas públicas contrárias à legislação nacional. Pesquisa exploratória e descritiva, revisão bibliográfica. utilizando-se método dedutivo.

PALAVRAS-CHAVE: Ativismo judicial; Caso Gomes Lund e outros vs. Brasil; Corte Interamericana de Direitos Humanos; Direitos Humanos; Papel político do judiciário.

\section{THE POLITICAL ROLE OF THE INTER-AMERICAN COURT OF HUMAN RIGHTS FOR EFFECTIVENESS OF FUNDAMENTAL RIGHTS IN BRAZIL}

\begin{abstract}
The objective is to analyze the political role of the judiciary for the implementation of minority human rights and the possibility of judicial activism by the IACHR. The concept of activism, legitimacy and limits to analyze the extent to which it allows the realization of fundamental rights is analyzed. The IACHR's actions and activism in the face of state sovereignty will be analyzed through the analysis of the Gomes Lund et al. Brazil, clashing head-on with the Amnesty Law, being characterized as activist action for condemning the implementation of public policies contrary to national law. Exploratory and descriptive research, literature review. using deductive method.
\end{abstract}

KEYWORDS: Judicial activism; Case of Gomes Lund and Others v. Brazil; Inter-American Court of Human Rights; Human rights; Political role of the judiciary.

\footnotetext{
${ }^{1}$ Doutoranda em Direito do Estado pelo Programa de Doutorado Interisntitucional DINTER USP-UFMS; Mestra em Fronteiras e Direitos Humanos pela UFGD; Bacharela em Direito pela UFMS; Graduanda em Ciências Sociais pela UFGD e Advogada. E-mail: elaine.dupas@gmail.com

${ }^{2}$ Doutora em Direito pela Pontifícia Universidade Católica de São Paulo - PUCSP. Professora do Mestrado Acadêmico e da Graduação em Direito da Universidade Federal de Mato Grosso do Sul -UFMS, Mato Grosso do Sul (Brasil) e professora do Programa de Doutorado Interisntitucional DINTER USP-UFMS. E-mail: lucianicoimbra@hotmail.com
} 


\section{INTRODUÇÃO}

O papel político do judiciário, ou ativismo judicial, é tema que suscita as mais diversas discussões e que encontra fundamentação teórica e prática para sua maciça defesa ou total repúdio.

Objetiva-se a análise do papel político e a possibilidade de atuação, por meio de ativismo judicial, da Corte Interamericana de Direitos Humanos no Caso da Guerrilha do Araguaia - Caso Gomes Lund e outros, no qual o Brasil foi condenado por ter pessoas desaparecidas no contexto da Guerrilha do Araguaia.

O ponto de controvérsia decorre do fato do país ter sido condenado também a implementar políticas públicas, bem como a instituição da Comissão da Verdade, para reparar os danos das vítimas e familiares, embora haja no Brasil a Lei de Anistia.

Para tanto, serão desenvolvidos os objetivos específicos: análise do papel político do judiciário em âmbito nacional, conceituado o termo ativismo judicial e sua legitimidade e limites para a efetivação dos Direitos Humanos, além de ser imprescindível tratar da separação dos Poderes, suas funções típicas e atípicas.

A teoria da separação dos Poderes inicia o debate ao conferir funções típicas e atípicas para o Poder Legislativo, Poder Executivo e Poder Judiciário. Porém, a cooperação entre os Poderes também deve ser trazida à tona para possibilitar estratégias institucionais que permitam o melhor funcionamento da Democracia, governança e proteção aos dos Direitos Humanos.

Posteriormente, serão abordados os conceitos de direitos do homem, direitos fundamentais e Direitos Humanos para então adentrar ao tema do ativismo para garantia de efetivação dos Direitos Humanos universais, utilizando o Caso da Guerrilha do Araguaia para ilustrar a atuação tendo como finalidade a igualdade fática e a efetivação de direitos.

Quanto aos fins, a pesquisa é exploratória e descritiva, com objetivo de demonstrar a atuação da Corte Interamericana para efetivação dos Direitos Humanos e direitos fundamentais por meio do ativismo, utilizando-se, para tanto, o método dedutivo. Quanto aos meios, a pesquisa é bibliográfica, foram coletados materiais a partir de livros, artigos científicos, legislações nacionais e internacionais, dissertações, teses de doutorado e relatórios de organizações internacionais. 


\section{O PAPEL POLÍTICO DO JUDICIÁRIO: LEGITIMIDADE E LIMITES PARA EFETIVAÇÃO DOS DIREITOS HUMANOS.}

A garantia da Constituição e dos direitos fundamentais é o maior objetivo do Estado Constitucional. No mesmo sentido e com igual importância, a soberania e o formalismo são os garantidores de tal efetivação e devem ser respeitados para que haja Democracia.

A separação dos poderes, descrita por Montesquieu (1996), constitui a estrutura para a modelagem do desenho institucional, centra-se em três ramos governamentais: Poder Executivo, Legislativo e Judiciário, e foi elaborada como forma necessária para prevenir e controlar o poder.

O Brasil segue a teoria da separação dos Poderes no texto constitucional a partir da Constituição de 1891, com algumas variações importantes de sentido e utilizando-se da teoria da nova separação de poderes, que tem como elemento essencial a cooperação (ACKERMAN, 2000).

Diante das modificações conceituais e de estrutura, percebe-se a deficiência da teoria da tripartição dos poderes e a necessidade de se repensar as funções típicas e atípicas para a possibilidade de efetivação dos direitos fundamentais e dos Direitos Humanos, distinção essa que será abordada sob a perspectiva de Sarlet (2012).

Diante da crise do Estado de Direito e "deflagração do "estado de coisas inconstitucional" - violação massiva dos Direitos Humanos - pelo Supremo Tribunal Federal [...]" que foi debatida massivamente a temática após os 30 anos da Constituição Cidadã de 1988 (GOUVÊA, 2019, p.2),

Sobre a necessidade da análise da tripartição dos poderes devido às novas configurações do judiciário, Barroso (2012) afirma sobre a excessivo número de casos que tiveram a decisões consideradas frutos do ativismo do judiciário:

Todos estes casos ilustram a fluidez da fronteira entre política e justiça no mundo contemporâneo. Ainda assim, o caso brasileiro é especial, pela extensão e pelo volume. Circunstâncias diversas, associadas à Constituição, à realidade política e às competências dos Poderes alçaram o Supremo Tribunal Federal, nos últimos tempos, às manchetes dos jornais. (BARROSO, 2012, p. 23) (grifos nossos) 
Para tanto, é mister pensar a evolução do papel do Poder Judiciário, que deve ser analisada para a compreensão de sua atividade nos dias atuais, e para que seja possível avaliar os benefícios e danos à democracia ao exercer o ativismo. Uma vez que no Brasil, passou-se a decidir mais por princípios do que por meio de normas, acirrando a discussão sobre o tema.

Há que se iniciar tal discussão por meio do conceito de ativismo judicial é amplo e suscita várias divergências doutrinárias. Será utilizada a conceituação conferida por Barroso (2012) que afirma:

O ativismo judicial é uma atitude, a escolha de um modo específico e proativo de interpretar a Constituição, expandindo o seu sentido e alcance. Normalmente ele se instala em situações de retração do Poder Legislativo, de um certo descolamento entre a classe política e a sociedade civil, impedindo que as demandas sociais sejam atendidas de maneira efetiva. (BARROSO, 2012, p.25)

Portanto, tratar-se-á, neste artigo, sob a perspectiva de inércia do Poder Legislativo e de impossibilidade de efetivação das demandas sociais devido à legislação, como é o caso que será abordado em tópico posterior sobre a condenação do Brasil pela Corte Interamericana de Direitos Humanos no caso popularmente conhecido como o Caso da Guerrilha do Araguaia.

Um dos fatores, também apontado por Barroso (2012), que colaborou para que o Poder Judiciário fosse tido como o agente capaz de concretizar a justiça, foi o fato dos julgamentos do STF serem transmitidos pela televisão, fazendo com que houvesse o empoderamento excessivo o poder judiciário, Barth (1974) afirma que "os juízes são "deuses do Olímpo" e a midiatização faz com que suas palavras sejam incontestáveis e concretizadoras da justiça. Havia um endeusamento e distanciamento entre a sociedade e os julgadores. Nesse sentido, afirma Barroso:

Acrescente-se a tudo isso a transmissão direta dos julgamentos do Plenário da Corte pela TV Justiça. Em vez de audiências reservadas e deliberações a portas fechadas, como nos tribunais de quase todo o mundo, aqui se julga sob o olhar implacável das câmeras de televisão. Há quem não goste e, de fato, é possível apontar inconveniências. Mas o ganho é maior do que a perda. (2012, p.23)

E complementa, corroborando com a ideia de Barth (1974) sobre o endeusamento dos magistrados, "os deuses do Olímpo":

Em um país com o histórico do nosso, a possibilidade de assistir onze pessoas bem preparadas e bem intencionadas decidindo questões nacionais é uma boa imagem. A visibilidade pública contribui para a 
transparência, para o controle social e, em última análise, para a democracia. (BARROSO, 2012, p. 23-24) (grifos nossos)

Entretanto, o fenômeno das redes sociais, principalmente observado nas eleições de 2018, modifica essa visão de superioridade que a sociedade tem do Poder Judiciário, de acordo com dados da FGV:

A partir de 2017, constatou-se uma queda da confiança da população no que se refere ao Poder Judiciário (-17\%). A taxa de confiança do brasileiro no STF é de 24\% em 2017 (FGV, 2017, p.13). Já as redes sociais obtiveram um aumento de $61 \%$ da confiança ao se analisar os anos 2016 e 2017 (FGV, 2017, p. 13). (FGV,2017)

E complementa Godoy (2019):

Assim, passou-se a notar uma mudança do polo doador de valor para a sociedade. Este fenômeno tornou-se evidente em 2018, em razão das eleições presidenciais e às duras críticas que o STF passou a receber em decorrência de suas decisões. Antes as decisões não eram questionáveis, eram consideradas justas e racionais, pois advinham de personalidades respeitáveis e de uma instituição venerada. Hoje, tanto os Ministros do STF como as próprias instituições são alvos de ataques da população que, cada vez mais, não os vêem como doadores de valores para as sociedades órfãs. (GODOY, 2019) (grifos nossos.)

Há uma mudança recente, no sentido do juiz já não ser mais detentor da vontade do povo e justiça, passando agora para uma realidade na qual pode ser vigiado pela sociedade, pelas redes sociais, que critica sua atuação e fornece informações, e, portanto, é cobrado pelo povo. Tal falta de credibilidade extrapola a figura do magistrado, chegando às instituições. Desse modo, há um processo que diminui a credibilidade e o status que o Poder Judiciário tinha diante da sociedade, como sujeito que fazia interpretação das normas jurídicas de forma justa e igualitária.

Nesse sentido, Godoy (2019, s.p) afirma que "o texto das leis deve ser preciso e determinado, reduzindo, ao máximo, o campo de interpretação, pois ambiguidades geram a ampliação do campo de atuação estatal no que se refere à aplicação das leis."

Portanto, a discussão sobre o ativismo judicial tem fundamento na ideia de que o Poder Judiciário e o Poder Executivo não deveriam se sobrepor ao Poder Legislativo, eleito democraticamente, e que expressa a vontade do povo. Assim, afirma LEAL (2014, p. 125):

[...] especialmente no que tange à sua legitimidade democrática, em face de uma - suposta - violação do princípio da separação dos po- deres, pois, ao tentar levar a cabo suas tarefas constitucionais, o Poder Judiciário acaba, muitas vezes, sendo acusado de invadir competências reservadas aos poderes públicos e à discricionariedade administrativa ou legislativa, atuando, assim, 
de forma positiva, e não meramente negativa, como originariamente era sua função.

As críticas ao ativismo judicial partem da ideia de suposta violação da separação dos poderes e estão assentadas no argumento do paternalismo, uma vez que os Tribunais decidem fundamentados em princípios, criando uma jurisprudência de valores, que passam a ser os "senhores da Constituição". (MAUS, 2000, s.p).

Tal análise parte de uma sociedade fragilizada que transfere para o judiciário o poder de decisão de certas questões não enfrentadas pelo Parlamento, nesse sentido que o Poder Judiciário é tido como um pai para um sociedade órfã. (MAUS, 2000)

Porém, atualmente, entende-se, na maioria dos casos, que o ativismo judicial não fere a democracia, possibilitando, muitas vezes, a efetivação dos direitos das minorias privadas de reconhecimento.

Embora haja várias criticas fundamentadas, neste artigo será adotada a ideia de que os benefícios estão associados à efetivação de direitos e garantias, ou seja, demostrar-se-á a necessidade da atuação do judiciário além de suas funções primárias, assim como os benefícios da decisão da Corte Interamericana no Caso Guerrilha do Araguaia.

Nesse mesmo sentido, Alves e Oliveira (2014, p.2), abordam o ativismo do judiciário com "fundamento na Constituição de 1988 para construir um ideal de igualdade fática, principalmente a partir das normas contidas nos $\S \S 1$ o e 20 do art. 5o.”, corroborando com a necessidade da atuação do judiciário para a garantia dos direitos das minorias, bem como da Democracia.

Em relação aos grupos minoritários, vale destacar o pensamento de Boaventura de Souza Santos (2003) que enfatiza as diferenças violadoras de direitos fundamentais e Direitos Humanos:

Temos o direito a ser iguais quando a nossa diferença nos inferioriza; e temos o direito a ser diferentes quando a nossa igualdade nos descaracteriza. Daí a necessidade de uma igualdade que reconheça as diferenças e de uma diferença que não produza, alimente ou reproduza as desigualdades. (2003, p. 56)

A igualdade pretendida é fática, material, e não apenas formal, com a máxima tutela de direitos fundamentais e dos Direitos Humanos. A definição usada no presente artigo é de Ingo Sarlet (2012, p. 30), que conceitua e difere as expressões direitos do homem, se referem a direitos naturais ainda não positivados; Direitos Humanos, referem-se a direitos 
positivados em âmbito internacional; $\mathrm{E}$ direitos fundamentais, que representam direitos outorgados e protegidos pelo direito constitucional interno de cada Estado.

De acordo com Rothenburg (2008, p. 86): “A igualdade de fato (material) será o resultado eventual da igualdade de direito (formal)." Logo, parte-se do pressuposto que para haver igualdade é necessário que haja ação, e o ativismo judicial é uma proatividade na busca pela efetivação da igualdade fática.

Nesse sentido, Alves e Oliveira (2014, p. 37) tratam da igualdade pela perspectiva de Bobbio: "Notadamente, para que se possa falar em igualdade é imprescindível um paradigma. Nesse sentido, quando se fala em igualdade, é antes necessário questionar: igualdade entre quem? e igualdade em quê?"

E, portanto, "cabe ao Direito [...] não apenas defender a igualdade contra violações, mas também promover a igualdade com distinções" (ROTHENBURG, 2008, p. 82), e o ativismo judicial pode ser via para efetivação de direitos visando a igualdade fática.

E, segundo Joaquín Herrera Flores:

Apesar da enorme importância das normas que buscam garantir a efetividade dos direitos no âmbito internacional, os direitos não podem reduzir-se às normas. Tal redução supõe, em primeiro lugar, uma falsa concepção da natureza do jurídico e, em segundo lugar, uma tautologia lógica de graves consequências sociais, econômicas, culturais e políticas. (2009, p.17)

Ou seja, há que se olhar e enfrentar as desigualdades para além das normas ao tratar de Direitos Humanos, há que se alcançar à esfera da concretização, a garantia deve ser fática porque as mazelas são. E é nesse ponto que se sustenta a necessidade do ativismo do judiciário defendida na busca de efetivação de direitos.

Portanto, em âmbito nacional é apontada a necessidade, diante da inércia do Poder Legislativo, da prática do ativismo visando a efetivação de direitos. Nesse mesmo sentido, será analisada a atuação da Corte Interamericana de Direitos Humanos, especificamente o caso Gomes Lund e outros ("Guerrilha do Araguaia") vs. Brasil.

Afinal, ter uma legislação, Lei de Anistia - Lei n. 6.683 de 28 de agosto de 1979, que concede anistia aos crimes cometidos no período de Ditadura Militar no Brasil, viola frontalmente os Direitos Humanos e impossibilita a implementação de políticas públicas, conforme determinado pela Corte Interamericana. 


\section{CORTE INTERAMERICANA DE DIREITOS HUMANOS E O CASO}

\section{“GUERRILHA DO ARAGUAIA": A EFETIVAÇÃO DOS DIREITOS HUMANOS FRENTE À SOBERANIA ESTATAL.}

Para a compreensão dos Tribunal Internacionais, é necessário breve histórico para contextualizar o surgimento e atuação, que em alguns aspectos, são bem parecidos com a jurisdição constitucional.

O conceito de soberania recebe dimensões distintas no âmbito interno e no âmbito externo, desprendendo-se da compreensão clássica associada à ideia de poder soberano relacionada aos monarcas absolutistas dentro do território governado por eles.

Afirma Leal (2014, p. 131):

Trata-se, assim, de um direito restitutivo, e não repressivo, de relações pautadas não pelo compartilhamento de sentimentos comuns, mas pelo respeito à diferença e à autonomia de cada um de seus sujeitos, que se obrigam por meio de contratos - neste caso, os Tratados - em que restam garantidas as prerrogativas de autodeterminação das partes. O principal escopo é, portanto, assegurar as esferas de atuação e de não-intervenção de cada Estado.

E complementa:

Já na esfera interna, verificou-se uma progressiva limitação do conceito, uma vez que "com a Declaração dos Direitos do Homem e do Cidadão, de 1789, e depois com sucessivas cartas constitucionais, muda a forma do Estado e, com ela, muda, até se esvaziar, o próprio princípio da soberania interna. (LEAL, 2014, p. 132)

Logo, pode-se falar em uma ordem supranacional, a partir do surgimento de Organizações e Tratados Internacionais, passando de um sistema baseado em tratados bilaterais para um ordenamento jurídico supraestatal.

Estados estão, cada vez mais, limitados em sua soberania, tanto interna quanto externa, há interdependência internacional, determinada por fatores políticos, econômicos e/ou militares, que leva a uma ideia de cooperação jurídica, mais do que a um reforço das concepções tradicionais de soberania. Ideia também transformada profundamente em razão de uma série de fatores, tais como: comunidades supranacionais; capitalismo financeiro com empresas transnacionais e Organizações não-governamentais.

A proteção dos Direitos Humanos ganhou destaque, na esfera internacional, com a criação de Tribunais e de Cortes Internacionais, que devem atuar na aplicação e julgamento 
de casos em que esteja configurada uma violação de tais direitos por parte dos Estadosmembros.

O controle de convencionalidade, de acordo com a própria Corte Interamericana de Direitos Humanos, refere-se:

[...] si los tribunales constitucionales controlan la "constitucionalidad", el tribunal internacional de derechos humanos resuelve acerca de la "convencionalidad" de esos actos. A través del control de constitucionalidad, los órganos internos procuran conformar la actividad del poder público --y, eventualmente, de otros agentes sociales-- al orden que entraña el Estado de Derecho en una sociedad democrática. El tribunal interamericano, por su parte, pretende conformar esa actividad al orden internacional acogido en la convención fundadora de la jurisdicción interamericana y aceptado por los Estados partes en ejercicio de su soberanía. (CORTE IDH, 2012, s.p)

Nesse sentido, a prática de ativismo judicial pode ser aplicado às Cortes Internacionais, e, para demonstrar tal possibilidade, será utilizado o caso em que houve condenação do Brasil a indenizar as famílias devido o sofrimento causado pelas não investigações efetivas, assim como pela negativa de acesso a essas informações por parte do Estado e que país deve processar e julgar, penalmente - por meio da justiça ordinária, comum - os responsáveis por tais atos. E, principalmente, pela condenação na qual:

Com efeito, o estabelecimento de uma Comissão da Verdade, dependendo do objeto, do procedimento, da estrutura e da finalidade de seu mandato, pode contribuir para a construção e preservação da memória histórica, o esclarecimento de fatos e a determinação de responsabilidades institucionais, sociais e políticas em determinados períodos históricos de uma sociedade. (CORTE IDH, 2010, p.106) (grifos nossos)

E complementa a decisão sobre a criação da Comissão da Verdade:

Por isso, o Tribunal valora a iniciativa de criação da Comissão Nacional da Verdade e exorta o Estado a implementá-la, em conformidade com critérios de independência, idoneidade e transparência na seleção de seus membros, assim como a dotá-la de recursos e atribuições que lhe possibilitem cumprir eficazmente com seu mandato. A Corte julga pertinente, no entanto, destacar que as atividades e informações que, eventualmente, recolha essa Comissão, não substituem a obrigação do Estado de estabelecer a verdade e assegurar a determinação judicial de responsabilidades individuais, através dos processos judiciais penais. (CORTE IDH, 2010, p.107) (grifos nossos)

Ainda de acordo com a sentença, "A Comissão também enfatizou o valor histórico do caso e a possibilidade de o Tribunal afirmar a incompatibilidade da Lei de Anistia e das leis sobre sigilo de documentos com a Convenção Americana." (CIDH, 2010, p. 
3). Porém, tal ponto é pacífico, na medida em que a legislação nacional viola substancialmente os Tratados Internacionais.

Trata-se também, de acordo com a sentença:

Conforme salientou a Comissão, a demanda se refere à alegada "responsabilidade [do Estado] pela detenção arbitrária, tortura e desaparecimento forçado de 70 pessoas, entre membros do Partido Comunista do Brasil [...] e camponeses da região, [...] resultado de operações do Exército brasileiro empreendidas entre 1972 e 1975 com o objetivo de erradicar a Guerrilha do Araguaia, no contexto da ditadura militar do Brasil (1964-1985)" (CORTE IDH, 2010, p. 3-4)

Logo, a problemática se dá devido à Lei de Anistia, vigente no país, explica LEAL (2014):

O que ocorre é que, assim como há ocorrido em outros países da América Latina (como Chile e Argentina, por exemplo), o Supremo Tribunal Federal havia, poucos meses antes, julgado constitucional a Lei da Anistia, entendendo que ela abarca todos os crimes praticados por ocasião do regime ditatorial (incluídos, aí, os crimes comuns, como homicídio, tortura, seqüestro e estupro), havendo este, inclusive, sido o principal argumento sustentado pela defesa do Brasil por ocasião de seu julgamen- to internacional. (LEAL, 2014, p. 134).

É ressaltado na decisão da corte tal fundamento apresentado pelo Brasil, que merece a transcrição destacada, para demonstrar a violação de um direito baseado em uma legislação nacional:

A Comissão também submeteu o caso à Corte porque, "em virtude da Lei no $6.683 / 79$ [...], o Estado não realizou uma investigação penal com a finalidade de julgar e punir as pessoas responsáveis pelo desaparecimento forçado de 70 vítimas e a execução extrajudicial de Maria Lúcia Petit da Silva [...]; porque os recursos judiciais de natureza civil, com vistas a obter informações sobre os fatos, não foram efetivos para assegurar aos familiares dos desaparecidos e da pessoa executada o acesso a informação sobre a Guerrilha do Araguaia; porque as medidas legislativas e administrativas adotadas pelo Estado restringiram indevidamente o direito de acesso à informação pelos familiares; e porque o desaparecimento das vítimas, a execução de Maria Lúcia Petit da Silva, a impunidade dos responsáveis e a falta de acesso à justiça, à verdade e à informação afetaram negativamente a integridade pessoal dos familiares dos desaparecidos e da pessoa executada". [...] (CORTE IDH, 2010, p.4)

Desse modo, estamos diante de uma lei que viola frontalmente os Direitos Humanos da vítimas e de seus familiares. No entanto, a dúvida levantada é em relação à Corte Interamericana poder adentrar na autodeterminação do Estado e determinar políticas públicas 
contrárias à legislação nacional com fundamento na reparação da violação aos Direitos Humanos.

Haja vista que o país foi condenado a criar políticas públicas, por meio da Comissão da Verdade para a implementação de ações sociais e públicas, de resgate da verdade e da memória, o que não foi realizado efetivamente até hoje, embora a CNV tenha sido criada.

Evidencia-se tal fato em um cenário político no qual o atual presidente do Brasil, Jair Bolsonaro, faz o seguinte pronunciamento, referindo-se ao desaparecido político Fernando Santa Cruz, pai do atual presidente da Ordem dos Advogados do Brasil $(\mathrm{OAB})$, Felipe Santa Cruz, em um vital desrespeito à memória das vítimas e famílias, embora não esteja relacionado diretamente com a Guerrilha do Araguaia, mas sim com o período de Ditadura Militar no país, bem como com a história brasileira, com a sociedade que até hoje sofre por não tere acesso às informações.

Destaca-se fala do presidente Jair Bolsonaro em matéria do site Folha de São Paulo $^{3}$ : "Um dia, se o presidente da OAB quiser saber como é que o pai dele desapareceu no período militar, eu conto pra ele. Ele não vai querer ouvir a verdade.” (FOLHA DE SÃO PAULO, 2019)

E de Dallari afirma em relação à manifestação do presidente, que independe de quem é a vítima, uma vez que tentasse se justificar os crimes cometidos no período de Ditadura Militar:

Mas isto não é o mais relevante. As famílias têm o direito de velar e sepultar seus filhos. Há dois documentos que indicam que o Fernando Santa Cruz esteve detido em repartição militar em fevereiro de 1974, portanto, ele estava custodiado pelo Estado brasileiro e depois desapareceu. Isto sim é grave. $^{4}$ (O GLOBO, 2019)

Ressaltamos que a história é construída também no tempo presente e sanção da lei $\mathrm{n}^{\mathrm{o}}$ 12.588, de 18 de novembro de 2011 instituiu a Comissão Nacional da Verdade com o

\footnotetext{
${ }^{3}$ FERNANDES, T.; COLETTA, R. D. Se presidente da OAB quiser saber como pai dele desapareceu na ditadura, eu conto, diz Bolsonaro. Disponível em:< https://www1.folha.uol.com.br/poder/2019/07/se-presidente-daoab-quiser-saber-como-pai-dele-desapareceu-na-ditadura-eu-conto-diz-bolsonaro.shtml>. Acesso em: 30 de jul de 2019.

4 Pedro Dallari em entrevista ao jornal O Globo. Após ataque de Bolsonaro ao presidente da OAB, simpatizantes do governo espalham boatos infundados sobre Fernando Santa Cruz. Disponível em: <https://politica.estadao.com.br/blogs/estadao-verifica/apos-ataque-de-bolsonaro-ao-presidente-da-oabrede-governista-espalha-boatos-infundados-sobre-fernando-santa-cruz/>. Acesso em: 30 de julho de 2019.
} 
objetivo de examinar e esclarecer as graves violações de Direitos Humanos praticadas na ditadura militar, tentando dar cumprimento à decisão da Corte.

Em relação à criação da Comissão da Verdade, ressalta-se:

A criação da Comissão Nacional da Verdade assegurará o resgate da memória e da verdade sobre as graves violações de direitos humanos ocorridas no período anteriormente mencionado [1946-1988], contribuindo para o preenchimento das lacunas existentes na história de nosso país em relação a esse período e, ao mesmo tempo, para o fortalecimento dos valores democráticos. ${ }^{5}$

Portanto, o ponto a ser discutido é se poderia a Corte Interamericana de Direitos Humanos ter determinado políticas públicas contrárias à legislação nacional vigente e impor uma série da ações aos diferentes órgãos estatais e em diferentes níveis. É nesse sentido que se vislumbra o ativismo praticado pela Corte, uma vez que em relação à condenação em si não há divergências, afinal, o Brasil é signatário de tratados internacionais que reconhece e se submete à jurisdição dos Tribunais Internacionais.

Diante do exposto, entende-se que a Corte Interamericana de Direitos Humanos atuou de maneira proativa para a efetivação dos direitos das vítimas e seus familiares. Afinal, uma condenação que não fosse capaz de extrapolar a forma, permanecendo como um direito abstrato, não cumpriria sua finalidade.

Nesse sentido, vislumbra-se tal decisão como prática de ativismo no sentido de efetivação dos Direitos Humanos. Mas não é possível afirmar que a soberania do Estado brasileiro foi preterida à uma soberania supranacional, mas sim como um meio de garantir que o direito interno fosse capaz de cumprir a sentença integralmente.

\section{CONSIDERAÇÃO FINAIS}

Entende-se que para a efetivação de direitos fundamentais e Direitos Humanos, o ativismo judicial é medida não apenas legítima, mas necessária diante da inércia e falta de interesse em agir, bem como posicionamento político dos outros Poderes, mesmo diante de

\footnotetext{
${ }^{5}$ Mensagem de 12 de maio de 2010 do presidente da República, Luiz Inácio Lula da Silva, ao Congresso Nacional, encaminhando o projeto de lei de criação da Comissão Nacional da Verdade. Disponivel em:< http://cnv.memoriasreveladas.gov.br/images/documentos/Capitulo1/Capitulo\%201.pdf>. Acesso em: 30 de julho de 2019.
} 
várias discussões e duras críticas que são suscitadas sobre a legitimidade e limites do papel político do Poder Judiciário.

Houve no Brasil e em vários países a modificação da maneira como a sociedade se relacionava e confiava no Poder Judiciário. Atualmente, as decisões, os magistrados e as Instituições sofrem ataques constantes e são cobrados por resultados rápidos e efetivos. E, portanto, a atuação do judiciário foi afetada por tais modificações. Afinal, decidir sobre casos complexos em transmissão ao vivo em rede nacional e, além disso, enfrentar as redes sociais que estão sendo utilizadas cada vez mais como campo de batalha para discussões políticas e jurídicas, é um desafio do tempo presente para a justiça, independente do Poder.

A Corte Interamericana de Direitos Humanos, ao condenar o Brasil em 2010, na decisão no Caso Guerrilha do Araguaia, atuou corretamente e nos limites de sua competência. E no que se refere à condenação para a criação de políticas públicas e sociais para reparar, dentro das possibilidades jurídicas, as violações sofridas pelas vítimas e famílias, também há uma justa atuação.

Por tratar-se de conceitos amplos e subjetivos, é uma tarefa de interpretação afirmar que ao condenar o Brasil à criação de políticas públicas contrárias à Lei de Anistia, a Corte estaria praticando o ativismo, utilizando-se da soberania supranacional em face da soberania nacional.

Defende-se, portanto, a ideia de cooperação entre os Poderes para que a igualdade fática seja alcançada. Desse modo, acredita-se que para a garantia dos Direitos Humanos é aceitável e imprescindível que o judiciário se posicione e faça cumprir a Constituição Federal e os Tratados Internacionais dos quais o país é signatário.

\section{REFERÊNCIAS BIBLIOGRÁFICAS}

ACKERMAN, Bruce. The New Separation of Powers. Vol 113, January 2000, N.03, Harvard Law Review, p.633-725.

ALVES, Fernando de Brito; OLIVEIRA, Guilherme Fonseca. Democracia e ativismo judicial: atuação contramajoritária do judiciário na efetivação dos direitos fundamentais das minorias. Argumenta - UENP, Jacarezinho/PR, 2014.

BARROSO, Luis Roberto. Judicialização, ativismo judicial e legitimidade democrática. (SYN)THESIS, Rio de Janeiro, 2012. 
BRASIL. Lei no 6.683, de 28 agosto de 1979. Concede anistia e dá outras providências. Disponível em: $<$ http://www.planalto.gov.br/ccivil_03/leis/L6683.htm>. Acesso em: 30 de jul 2019.

CORTE IDH. Caso Gomes Lund y Otros (Guerrilha do Araguaia) Vs. Brasil. Sentencia de 24 de noviembre de 2010.

FGV. Relatório ICJBrasil 1'semestre/2017. São Paulo: FGV, 2017. Disponível em: <<https://direitosp.fgv.br/sites/direitosp.fgv.br/files/arquivos/relatorio_icj_1sem2017.pdf〉>. Acesso em 30 jul de 2019.

Gouvêa, Carina, "a teoria da separação dos poderes em 30 anos de constituição democrática brasileira: o esquecido papel da cooperação para contemplar o todo perfeito do desenho institucional". In: BARROSO FILHO, José. (Coord). 30 anos da Constituição do Brasil de 1988: nosso projeto de futuro. Disponível em: <https://ssrn.com/abstract=3329942 or http://dx.doi.org/10.2139/ssrn.3329942>. Acesso em: 30 de jul de 2019.

HERRERA FLORES, Joaquín. A (Re) invenção dos direitos humanos. Florianópolis: Fundação Boiteaux, 2009. p. 232

LEAL, Mônia Clarissa Hennig. Corte Interamericana de Direitos Humanos e jurisdição constitucional. Revista de Investigações Constitucionais, $\left[\begin{array}{lll}S . & l .\end{array}\right]$ 2014. Disponível em: https://dialnet.unirioja.es/servlet/articulo?codigo=5839979. Acesso em: 30 jul. 2019.

MAUS, Ingeborg. Judiciário como superego da sociedade: o papel da atividade jurisprudencial na "sociedade órfã". In Novos Estudos, n. 58, , nov./2000, pp. 183-202. Disponível em: <<http://www.direitocontemporaneo.com/wpcontent/uploads/2014/02/JUDICI\%C3\%81RIO-COMO-SUPEREGO-DA-

SOCIEDADE.pdf $\gg>$. Acesso em 31 de jul de 2019.

MONTESQUIEU, Charles de Secondat, Baron de. O espírito das leis. São Paulo: Martins Fontes, 1996.

ROTHENBURG, Walter Claudius. Igualdade material e discriminação positiva: O princípio da isonomia. Novos Estudos Jurídicos, v. 13, n. 2, p. 77-92, 2009.

SANTOS, Boaventura de Sousa. Reconhecer para libertar: os caminhos do cosmopolitismo multicultural. Rio de Janeiro: Civilização Brasileira, 2003.

SARLET, Ingo Wolfgang. A eficácia dos direitos fundamentais: uma teoria geral dos direitos fundamentais na perspectiva constitucional. 11. ed. rev. atual. Porto Alegre: Livraria do Advogado Editora, 2012. 